\title{
Coronary Arteries Arising from Single Coronary Ostium: A Case Report
}

\author{
Cenk Conkbayir, ${ }^{1}$ Ugur Coskun, ${ }^{2}$ Didem Melis Oztas, ${ }^{3}$ Metin Onur Beyaz, ${ }^{4}$ Mert Meric, ${ }^{5}$ Murat Ugurlucan ${ }^{5}$
}

${ }^{1}$ Department of Cardiology, Near East University School of Medicine, Nicosia, Cyprus; ${ }^{2}$ Department of Cardiology, Kyrenia University School of Medicine, Karakum, Kyrenia, Cyprus; ${ }^{3}$ Department of Cardiovascular Surgery, Bagcilar Education and Research Hospital, Istanbul, Turkey; ${ }^{4}$ Department of Cardiovascular Surgery, Sultanbeyli State Hospital, Istanbul, Turkey; ${ }^{5}$ Department of Cardiovascular Surgery, Istanbul Medipol University Medical Faculty, Istanbul, Turkey

\section{ABSTRACT}

Advanced diagnostic systems and healthcare screening programs enabled increased diagnosis of congenital cardiovascular anomalies, including variations in coronary arteries. Single coronary artery is a rare congenital cardiovascular malformation in which all three main coronary arteries originate from a single coronary trunk.

In this report, we present a patient with single coronary ostium giving rise to the left and right coronary artery systems, which was diagnosed incidentally with coronary computerized tomography and confirmed with conventional angiography.

\section{INTRODUCTION}

Cardiovascular problems-especially coronary artery disease-constitute the leading cause of death in the developed world [Yaymaci 2010]. The number of patients screened with non-invasive diagnostic methods for the diagnosis of coronary artery pathologies increase rapidly in the current era. As a result, congenital coronary variations are more frequently encountered.

In this report, we present single coronary trunk rising from the left and right main coronary artery systems.

Case Report: The patient was a 63-year-old male admitted to the institution, complaining about a burning sensation in his chest following exercise. He had been a smoker for more than 25 years. He was obese (BMI: $28.9 \mathrm{~kg} / \mathrm{m}^{2}$ ) and hypertensive $(145 / 90 \mathrm{mmHg})$.

Electrocardiography and echocardiography were unremarkable. He underwent stress during his electrocardiography, which ceased after six minutes because he was tired and hypertensive. We decided to perform coronary computerized tomography angiography to evaluate the patient's coronary arteries. This revealed single coronary ostium (right) giving rise to the left main coronary artery and right coronary artery (Figure 1).

Received November 25, 2019; received in revised form March 29, 2018; accepted April 27, 2019

Correspondence: Cenk Conkbayir, MD, Near East University, Department of Cardiology, Nicosia/Cyprus; +90 5338775042 (e-mail: cenkconk@ botmail.com).

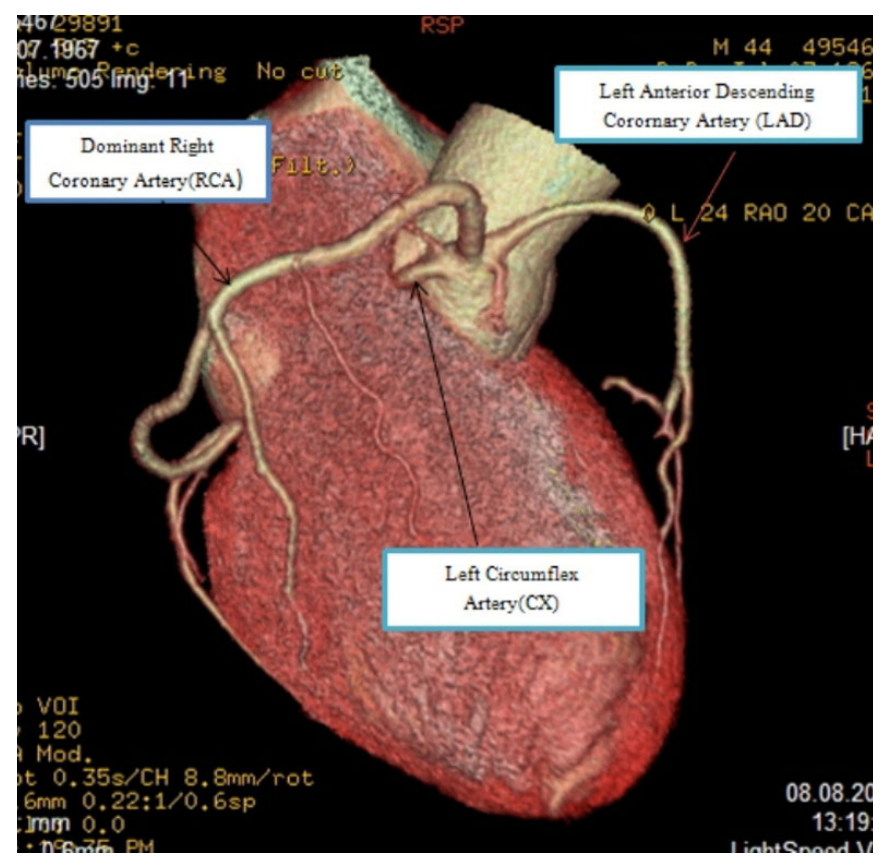

Figure 1. Coronary computerized tomography angiography showing single coronary artery originating from the right coronary sinus and giving rise to the coronary arteries.

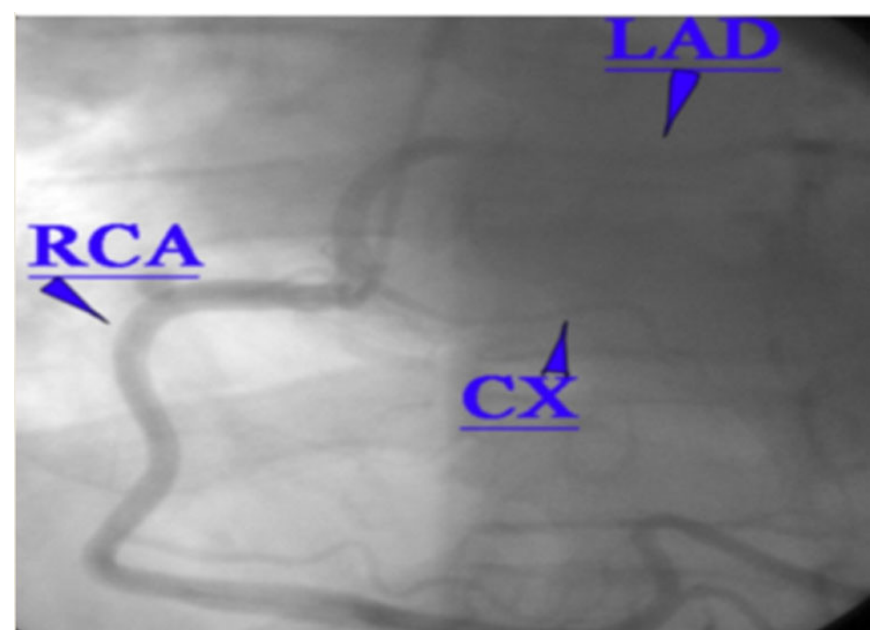

Figure 2. Conventional coronary angiography showing the solitary coronary artery giving rise to all branches. 
There were calcifications leading to significant and minor stenosis at the course of the circumflex and left anterior descending coronary arteries, respectively. Further diagnostic work up with angiography confirmed right solitary coronary ostium giving rise to the dominant right coronary artery, circumflex coronary artery, and left anterior descending artery without high grade stenosis (Figure 2). We decided to perform regular follow-up and started antihypertensive therapy with beta-blockers, Aspirin 100mg/ day, and life style modifications.

\section{DISCUSSION}

Single coronary artery anomaly has an incidence of $0.026-$ $0.4 \%$ in the population [Yaymaci 2010; Desmet 1992; Lipton 1979] and accounts for $<3 \%$ of congenital coronary anomalies [Yaymaci 2010] with no gender preference. They may accompany congenital cardiac pathologies. They are coincidentally detected during coronary investigations in adult populations. Coronary anomalies are challenging, during percutaneous coronary interventions and surgery.

There is no strong association between the solitary coronary artery and myocardial events. It is usually clinically silent and does not affect a patient's life expectancy or quality of life [Saglam 2017]. Anomalous origin of one coronary artery from the pulmonary artery may mimic solitary coronary artery, but it leads to severe suppression of myocardial functions in early years of life.

Cardiovascular anomalies are more commonly encountered with the frequent use of radiographic diagnostic tools for the diagnosis and screening of patients. Especially the noninvasive nature of the computerized tomography and enhanced image quality enabled computerized tomography is a more frequently used tool in patients highly suspected for coronary artery disease. However, conventional coronary angiography is the gold standard method to precisely detect coronary artery disease [Bayram 2008].

There is no definite information whether single coronary artery anomaly leads to cardiac problems in the literature. Garg et al indicate solitary coronary artery is not associated with increased risk for coronary atherosclerosis [Garg 2000]. On the other hand, Porto et al state that risk of atherosclerosis is increased in the case of single coronary artery resulting from acute angles [Porto 2004].
Coronary spasm [Yamamoto 1981], angina pectoris, and myocardial infarction are also reported in patients with single coronary artery in the absence of coronary stenosis [Joswig 1978]. As a result, percutaneous angioplasty and stenting in the presence of single coronary artery has also been reported [Porto 2004].

In conclusion, solitary coronary artery is a rare congenital anomaly. In our case, all three coronary arteries arose from the right coronary sinus and followed their usual courses on the epicardium.

\section{REFERENCES}

Bayram E, Kocatürk H, Kantarci M, Fil F, Colak MC. 2008. Anomalous origin of the right coronary artery arising from the left anterior descending artery in a case with single coronary artery anomaly: multi-detector computer tomography imaging. Anadolu Kardiyol Derg. 8(5):385-6.

Desmet W, Vanhaecke J, Vrolix M, Van de Werf F, Piessens J, Willems J, de Geest H. 1992. Isolated single coronary artery: a review of 50,000 consecutive coronary angiographies. Eur Heart J. 13:1637-40.

Garg N, Tewari S, Kapoor A, Gupta DK, Sinha N. 2000. Primary congenital anomalies of the coronary arteries: A coronary arteriographic study. Int J Cardiol 74:39-46.

Joswig BF, Warren SE, Vieweg WV, Hagan AD. 1978. Transmural myocardial infarction in the absence of coronary arterial luminal narrowing in a young man with single coronary arterial anomaly. Cathet Cardiovasc Diagn 4:297-301.

Lipton MJ, Barry WH, Obrez I, Silverman JF, Wexler L. 1979. Isolated single coronary artery: Diagnosis, angiographic classification and clinical significance. Radiology 130:39-47.

Porto I, Banning AP. 2004. Unstable angina in a patient with single coronary artery. Heart 90:858.

Saglam M, Dogan D, Sahin S, Turkkan C, Kula O. 2017. Single right coronary artery with absence of the left main coronary artery, left anterior descending artery, and circumflex artery. Echocardiography. 34(9):1401-1403.

Yamamoto K, Koiwaya Y, Tajimi T, Inou T, Mitsutake A, Orita Y, Takeshita A, Nakamura M. 1981. Coronary arterial spasm in single coronary artery. Circulation 64:1287-1290.

Yaymaci B, Ugurlucan M, Basaran M, Selimoglu O, Kocailik A, Akyildiz S, Coskun O, Us M. 2010. Solitary coronary artery nourishing the entire heart. Ann Saudi Med. 30(1):81-3. 